\title{
Thickener feedwell internal trough slurry distribution method
}

\author{
SM Viduka Metso Outotec, Australia
}

B Henriksson Metso Outotec, Australia

\begin{abstract}
This paper presents a numerical and experimental investigation of an innovation in thickener feedwell technology. A feedwell plays a leading role in the robust operation of a thickener. Its multifunctional duties include slurry feed momentum dissipation, solids and liquor mass fraction preparation, flocculation, and symmetrical aggregate delivery to the tank.

The testing of new concepts in the pursuit of developing a next generation feedwell presented an opportunity to create an improvement in process performance.

An alternative method of using a feedwell trough, populated by a multitude of vertically directed nozzles, is adopted. These deliver slurry into a flocculation chamber before dispersing through an exit gap into the thickener tank. The trough most innovatively ensures flash mixing, and highly uniform solids dispersion inside the aggregate growth chamber.

Initial examination adopted a multiphase Eulerian mathematical model to explore geometric configurations under various process scenarios. Numerical modelling indicated that when quantitatively compared to an equivalently sized diluting Vane Feedwell ${ }^{T M}$ the design provides a large improvement in solids hold-up, mixing, exit distribution, and more.

Modelling advanced to onsite testing of a non-diluting small $2 \mathrm{~m}$ diameter prototype in an industrial mineral processing plant. The retrofitted feed system improved thickener performance when compared to the pre-existing feedwell and at a newly higher throughput duty. The first occurrence of a networked bed was observed, underflow densities improved by $6.5 \% \mathrm{w} / \mathrm{w}$, flocculant consumption reduced by $5 \%$, and overflow clarity largely improved. Underpinned by this positive result, modelling has shown even greater benefits may be found in application of the new technology to self-diluting feedwells.
\end{abstract}

Keywords: feedwell, flocculation, thickening, computational fluid dynamics, experimentation

\section{Introduction}

Similarly, both a thickener and a clarifier are used in a wide variety of industries as slurry dewatering devices to separate the solid and liquor fractions, therefore, a high fraction of solids exit as underflow, and inversely a high fraction of liquor passes as overflow.

Many of these devices are constructed with a predominant feature in terms of overall performance, which is a feedwell apparatus. A feedwell is usually centrally located within the tank into which the influent material stream is delivered. The most basic goal of a feedwell is to dissipate the incoming kinetic energy and uniformly discharge the material into the available tank settling area. A historically significant development in feedwell technology has been the addition of flocculant to bind particles into large dense aggregates which settle faster. This has vastly increased the operational unit throughput and thus given rise to the high-rate thickener which has largely superseded the conventional thickener. The adoption of flocculant has placed more demands on the feedwell design by adding to its operating complexity. To be an effective aggregate growth apparatus a feedwell must promote flocculation, which requires a multifaceted approach. An environment must be prepared so that the solids concentration inside the feedwell is optimum and homogeneous. The capability of homogenising solids, dilution liquor, and flocculent together is essential. An appropriate amount of residence time is needed so that floccules can grow and mature. Lastly, gentle 
material discharging becomes even more important when using flocculant as fragile aggregates can easily break in the presence of shear forces, thus nullifying the advantage of harnessing flocculation.

An overview of feed system designs was described by Jewell \& Fourie (2015). Various equipment suppliers have produced their own feedwell geometries, dilution methods, and flocculant dosing strategies to achieve the best possible performance. Additionally, many scientific investigations have focused on improving feedwell performance (Fawell et al. 2009).

The research and development presented in this paper on a next generation feedwell has resulted in a new feedwell design, and the concept is supported by computational modelling and process plant validation. The unique emerging feature is its ability to flash mix, of which the repercussion is a widespread improvement in all feedwell process functions.

\section{$2 \quad$ New small feedwell trough and flocculation chamber geometry}

A prospective $2 \mathrm{~m}$ self-diluting feedwell geometry is shown in Figure 1. This size is considered to fit within a 'small' category range of the Metso Outotec feedwell size range. In comparison to the Vane Feedwell, the incorporated feed trough is capable of homogenously distributing feed without the need of vanes, baffles, or directional Autodil ports-these are major simplifications. Directly below the trough, the flocculation chamber, and further below the exit geometry, do not change from the Vane Feedwell, likewise adopting the same cylindrical sidewall and deflector cone.

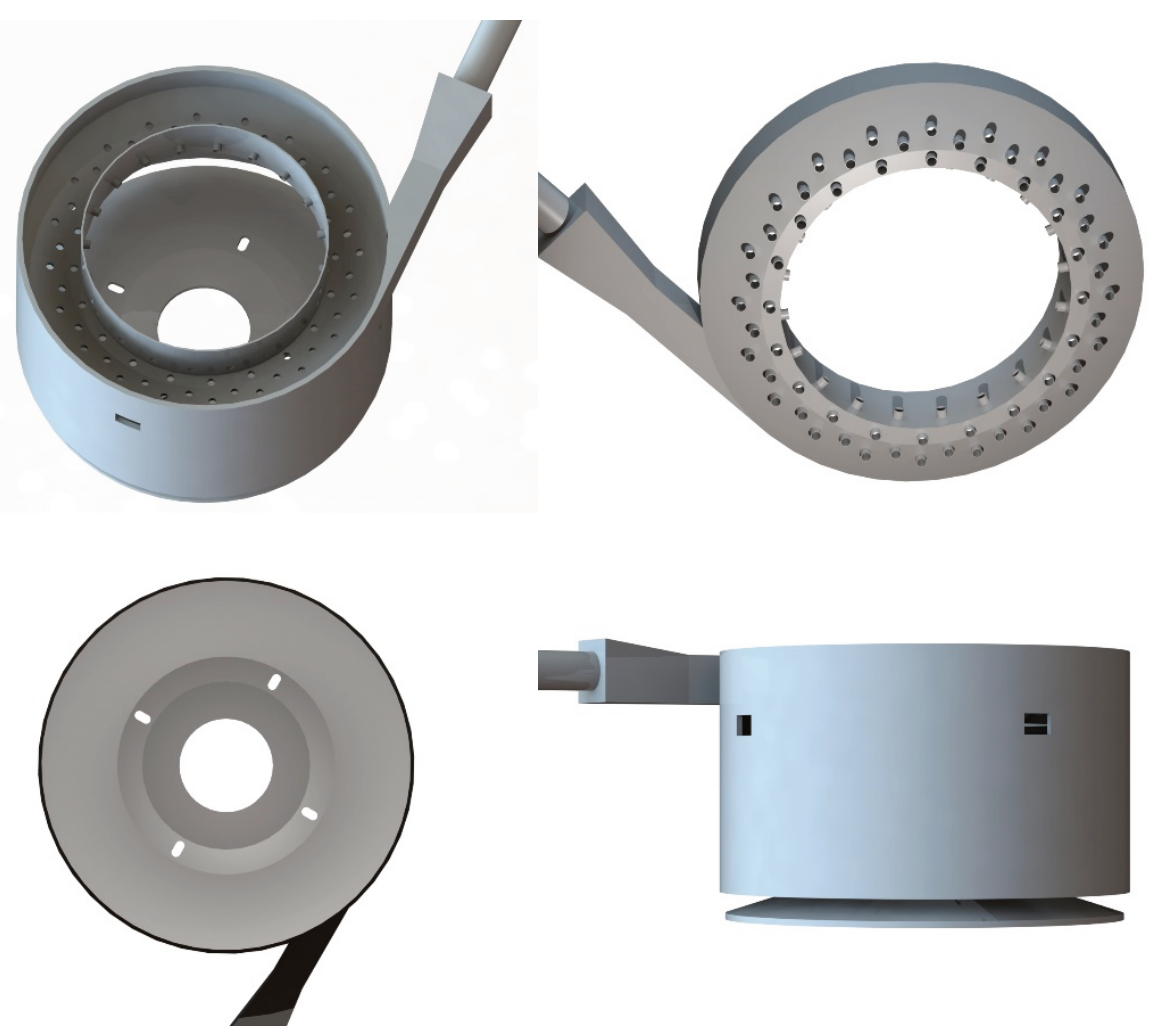

Figure 1 Geometry of new feedwell design showing a feed trough as a particularly unique feature

The design operates by the trough geometrically dividing the single slurry stream received from the feedpipe into numerous circumferentially equispaced streams, dispersing the feed before it enters the flocculation chamber. As the slurry passes through the trough it is directed vertically downwards by short nozzles, eliminating almost all the initial kinetic energy of the feed stream. A benefit of these features is the novel ability to flash mix solids and liquor, then distribute slurry uniformly within the feedwell chamber. The outcome is high volumetric efficiency. All other key performance indicators also improve. 
Auto diluting slots are located to compliment mixing by delivering dilution liquor in an orthogonal direction to the nozzle slurry stream. The slots are numerous and evenly spaced circumferentially on the vessel sidewall, with the number and size of slots optimised for the application and required dilution flow rate. The remainder of the chamber is a relatively calm environment where flocculation can develop before the aggregates exit through the deflector plate gap.

Precautions are made to eliminate the potential for sanding in the feed channel. The design does not only rely on numerous perforations disallowing settling and eventually a build-up of material within the trough. The trough is designed with an angled floor, and the channel volume is such that the design entry feed velocity is largely sustained, thereby constantly flushing the floor. Wear has been considered as a significant design factor as the high channel velocity may induce particle scouring. Therefore, it is seen to be practical to construct the channel from replaceable reinforced polyurethane segments or other abrasive resistant solutions as the application demands.

\section{$3 \quad$ Numerical modelling performance analysis}

It is a formidable task to use physical experiments to evaluate feedwell design. Not only expensive and time consuming, it lies in the difficulty to execute in situ measurements of a broad range of performance parameters. Therefore, it is preferable to adopt computational fluid dynamics (CFD) as an initial probe into feedwell fluid dynamics. An Eulerian-Eulerian steady-state multiphase simulation adopting a standard $\mathrm{k}-\varepsilon$ turbulence model of the full-scale feedwell and tank was used as a design tool.

A feedwell performance improvement may be achieved by favourably influencing the following key parameters: high feed kinetic energy dissipation; greater solids hold-up; approaching perfect homogeneous preparatory mixing of solids/liquor/flocculant; an aggregate growth region of gentle and low shear rate mixing; a high solids exit symmetry; a low solids exit energy; and low solids exit shear rate.

In regard to the thickener performance, the outcome will be: increased unit area throughput; higher settled density; improvement in overflow clarity; more stability; homogeneous solids collection; and a reduction in flocculant consumption.

An influent stream of a midrange $20 \% \mathrm{w} / \mathrm{w}$ solids concentration was chosen as a baseline in an effort to make an impartial presentation of the new design. A feedwell can exhibit high performance when filled with a low solids concentration as mixing is comparatively easy. Inversely, a higher concentration is prone to short circuiting. Investigations have been carried out over a concentration range of 3.5 to $47.5 \% \mathrm{w} / \mathrm{w}$. The design has been found to perform equally by using a range of trough and nozzle selections. The new design robustly manages feed variation in line with our experience in the majority of thickener and clarifier applications without significant performance impact. In some instances where there is significant risk of poor performance due to feed variation, alternative design solutions would be sought.

\subsection{Internal solid flow paths}

A feed stream of $20 \% \mathrm{w} / \mathrm{w}$ solids concentration is shown to dilute to $9 \% \mathrm{w} / \mathrm{w}$ inside a $2 \mathrm{~m}$ feedwell in Figure 2a. The streams indicate that the solids utilise the entirety of the trough before being distributed into the flocculation chamber where mixing with flocculant occurs and aggregates develop.

Despite the presence of numerous $45 \mathrm{~mm}$ diameter nozzles, to mitigate the risk of sanding the trough maintains the design influent velocity. The velocity shown in Figure $2 \mathrm{~b}$ closley matches that of the inlet region which from past experience has never had issues with sedimentation. Slurry at this velocity helps flush and avoid solids settling on the trough floor. Again, the angled floor slope is also seen to circumvent sanding. 


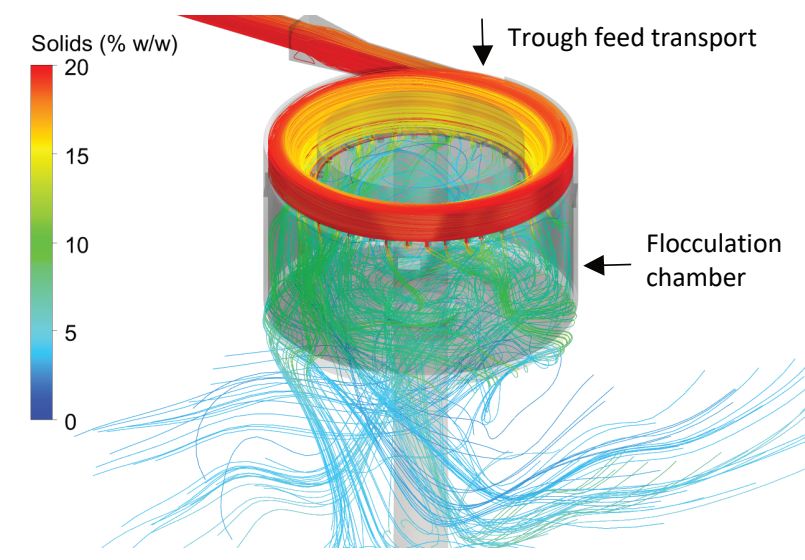

(a)

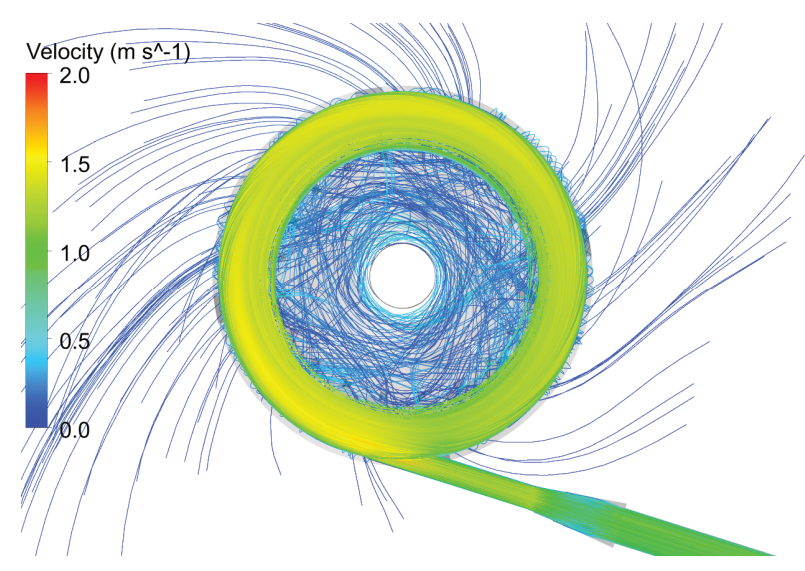

(b)

Figure 2 Solids mass fraction (a), and velocity (b), streamlines show maximum feedwell utilisation

\subsection{Solids concentration distribution}

It is evident from Figure 3 that this feedwell exhibits high solids retention inside the flocculation chamber, and that its volume is well utilised. A high degree of mixing is exemplified by a very homogenous solids distribution below the trough. Flash mixing becomes apparent in the step-change reduction in solids concentration directly beneath the trough. An evenly distributed solids concentration lends to a much higher potential of success in the application of a clarometer or a camera which can aid in optimising flocculant dosing.

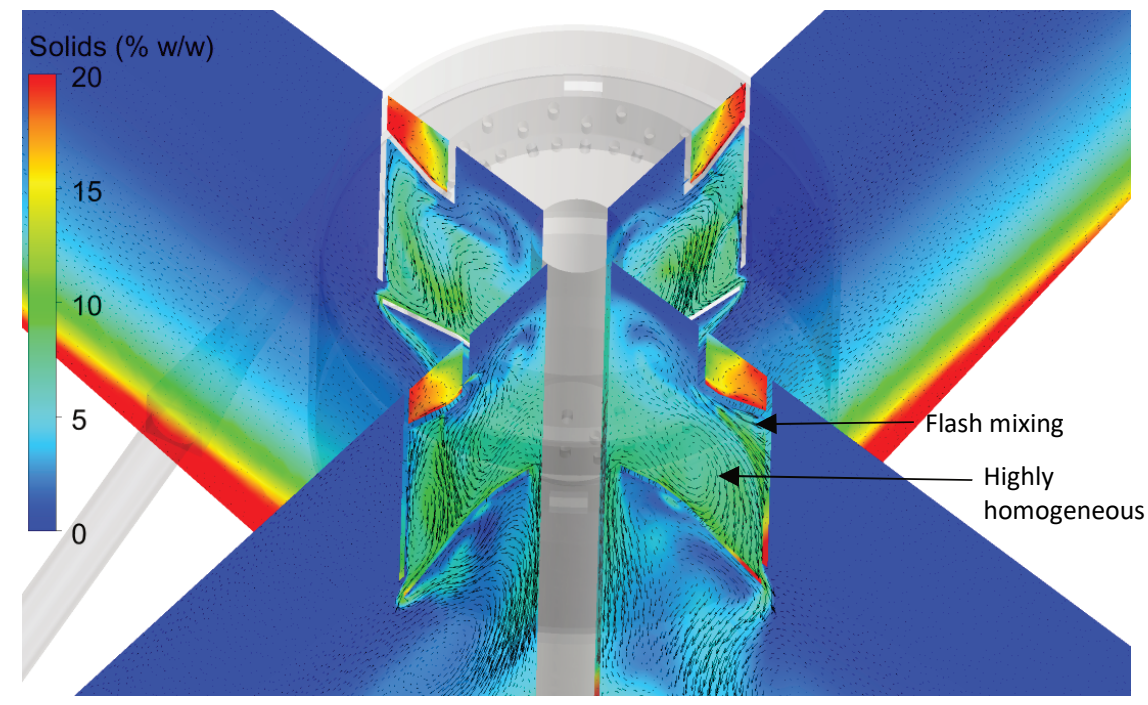

Figure 3 Solids mass fraction elevation contours reveal highly homogenous internal solids distribution

\subsection{Exit distribution}

The material exit distribution in the form of velocity vectors coloured according to a variety of physical quantities are shown in Figure 4. The solids concentration shown in Figure 4a is highly symmetrical, thereby distributing the material evenly throughout the thickener and maximising the utilisation of the tank settling area. This also assists in mud bed material transportation and alleviates the chance of beaching. It is important to keep the exit shear rate as low as possible to prevent aggregate breakage. Operating at least partially with exit gap shear rates of $200^{s-1}$ have shown to perform well in process plants. Figure $4 \mathrm{~b}$ shows that not only is the exit shear uniform, it is on average well below $200^{s-1}$. Asymmetric energy discharge at the exit may create plumes of solids that can stir up the mud bed and not only disrupt densification but increase the potential of solids reporting to the overflow. The energy flux shown in Figure $4 c$ is again highly symmetrical. 


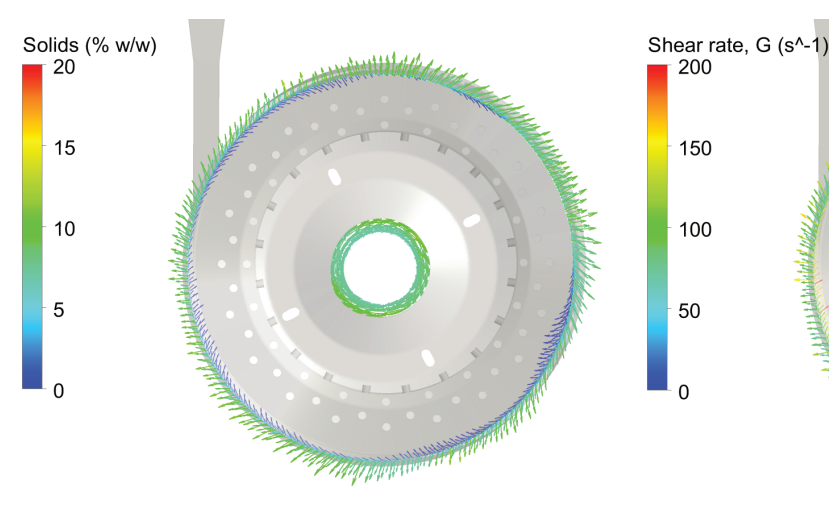

(a)

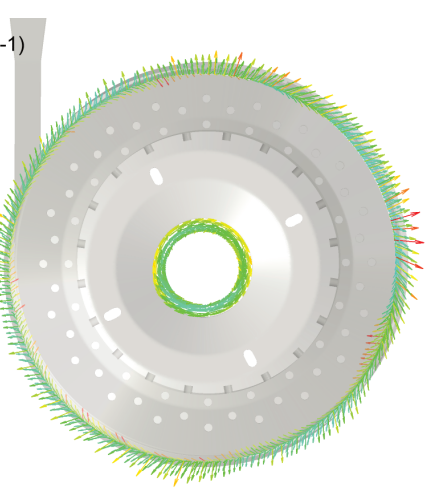

(b)

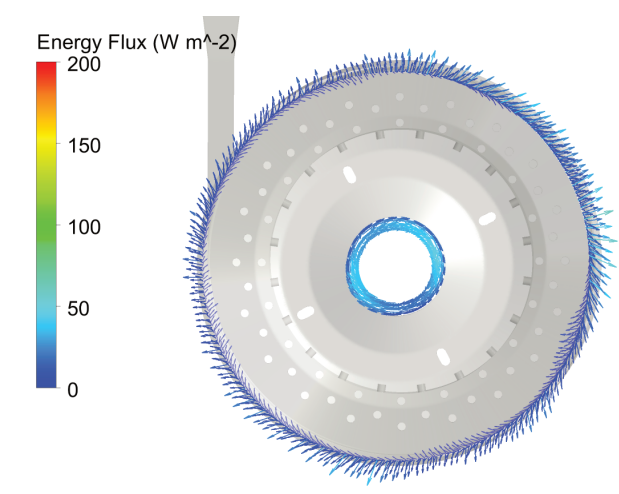

(c)

Figure 4 Highly symmetrical solids exit distribution over multiple physical parameters. (a) Solids concentration; (b) Shear rate; (c) Energy

\subsection{Comparison of the new small feedwell design to an equivalent Vane Feedwell ${ }^{\mathrm{TM}}$}

The Vane Feedwell from Metso Outotec, released in 2008, was the result of many years of internal research including numerical and physical experimentation. It is a proven technology with a strong track record of outperforming conventional equipment.

The new design and the Vane Feedwell can be divided into two distinct operating volumes; these in practice are difficult to delineate. An initial region exists in which the material preparation for flocculation takes place, and a secondary region in which flocculation occurs. Solid retention time is essential in the aggregate growth region; the higher the solid hold-up the best chance for complete floccule maturation. This region for the Vane Feedwell can be considered as the space beneath the vanes, while it can be considered as the space below the trough in the new design. Applying this rationale, the new design exhibits $50 \%$ more total solid hold-up.

Statistically quantified exit gap variables-by way of standard deviations-can be found in Table 1 . Comparatively, the new design delivers a far more symmetrical spread of solids concentration (-43\%), velocity $(-75 \%)$, energy distribution (-93\%), and mass flow (-50\%). It does so with approximately half the shear rate whilst the maximum energy values are overall far less.

Table 1 The Vane Feedwell and equivalent new design exit distribution statistics

\begin{tabular}{|c|c|c|c|c|c|c|c|c|}
\hline $\begin{array}{l}\text { Feedwell } \\
\text { type }\end{array}$ & $\begin{array}{l}\text { Solids } \\
\text { (\% w/w) }\end{array}$ & $\begin{array}{l}\text { SD } \\
\Delta \%\end{array}$ & $\begin{array}{l}\text { Velocity } \\
\text { (m/s) }\end{array}$ & $\begin{array}{l}\text { SD } \\
\Delta \%\end{array}$ & $\begin{array}{l}\text { Energy } \\
\left(\mathrm{J} / \mathrm{m}^{2} \mathrm{~s}\right)\end{array}$ & $\begin{array}{l}\text { SD } \\
\Delta \%\end{array}$ & $\begin{array}{l}\text { Mass flow } \\
(\mathrm{kg} / \mathrm{s})\end{array}$ & $\begin{array}{l}\text { SD } \\
\Delta \%\end{array}$ \\
\hline Vane & 2.76 & \multirow{2}{*}{-43} & 0.16 & \multirow{2}{*}{-75} & 43.74 & \multirow{2}{*}{-93} & 0.0006 & \multirow{2}{*}{-50} \\
\hline New & 1.58 & & 0.04 & & 3.15 & & 0.0003 & \\
\hline
\end{tabular}




\section{$4 \quad$ Prototype experimental evaluation}

A prototype platform consisting of a high-rate thickener in an industrial mineral application originally operating a non-diluting feedwell at $5 \% \mathrm{w} / \mathrm{w}$ feed concentration was used for evaluation. As mentioned previously, the new design excels most when dilution is required due to the flash mixing capability. Nevertheless, this does test whether the flow dynamics and flocculation mechanics are as intended.

\subsection{Computational fluid dynamic prototype modelling and design}

Initially, a review was conducted using computational methods to design the prototype feedwell. Figure 5 shows that all the applicable benefits of the new design have carried over to this case study.

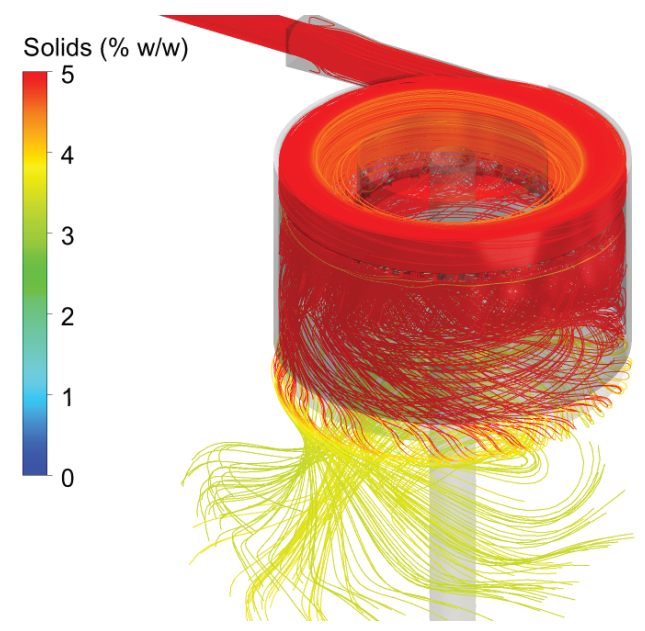

(a)

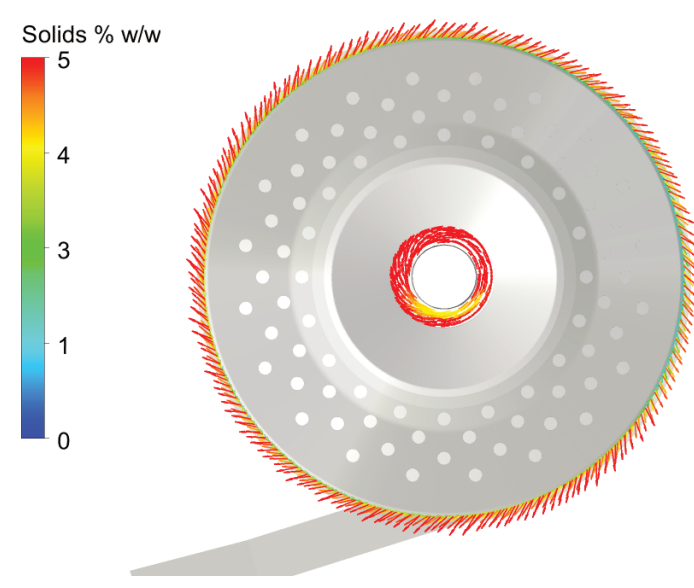

(c)

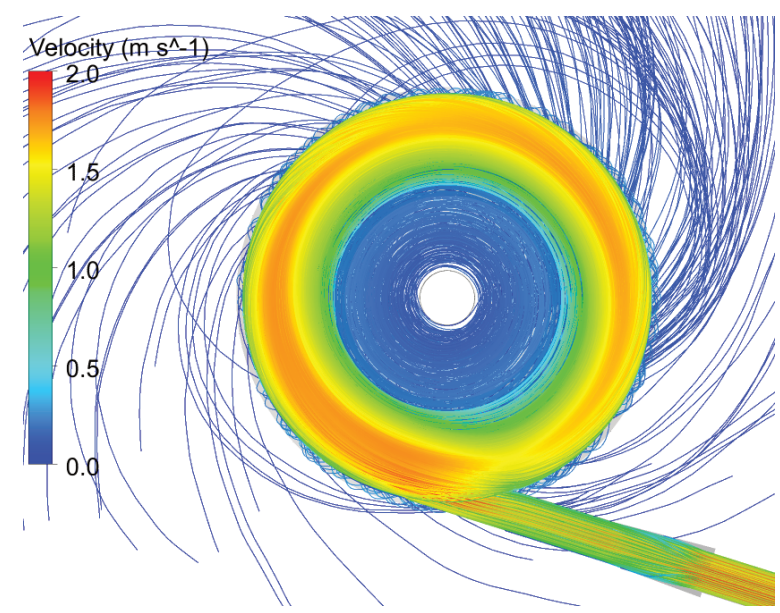

(b)

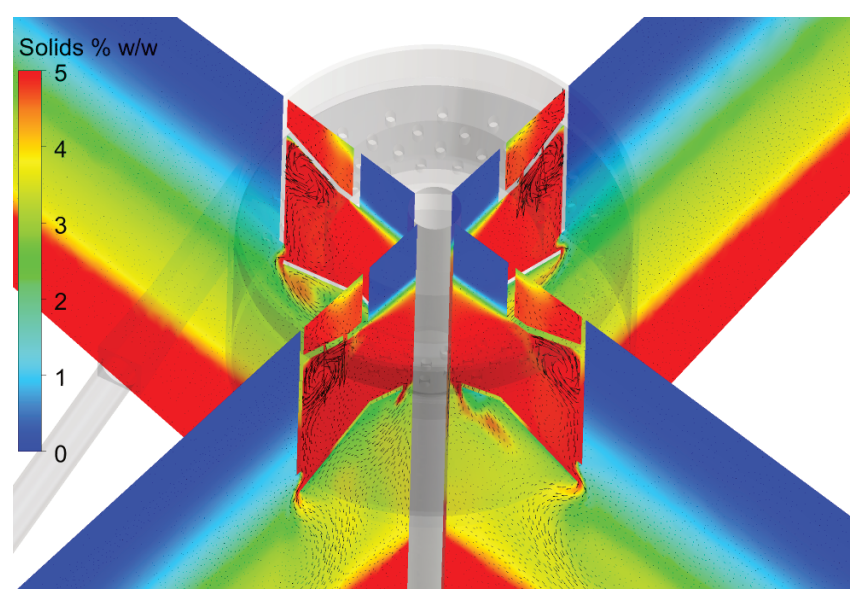

(d)

Figure 5 Solids mass fraction (a), and velocity (b), streamlines; solids exit distribution (c), and solids mass fraction elevation contours

\subsection{Operating plant protype evaluation}

The original feedwell was of an outdated design, ca. 1998, where the design consisted of a cylindrical shell, closed bottom, and internal baffles. The tank was refitted with the prototype feedwell. An elevation-cut perspective of the feedwell can be seen in Figure 6.

In practice, it is difficult to isolate the performance of the thickener from the rest of the plant. The thickener throughput remained equivalent before and after prototype installation, however, a performance improvement has resulted in a higher average throughput due to the effect of improved circuit stability. Reported by way of visual inspection, the thickener unprecedently developed a mud bed which covered the 
rakes. This is unsurprising since data collection revealed an average of a $6.5 \% \mathrm{w} / \mathrm{w}$ increase in underflow density-a $40 \%$ increase. Consequently, underflow pump speed reduced by an average of $29 \%$. The upgrade also reduced flocculant dosing by an average of $5 \%$. Figure 7 attempts to display the difference in clarity by comparing before and after photos in the absence of an operational turbidity meter.

Although the data is not definitive in the precise contribution the new feedwell had in the process improvements as compared to a modern Vane Feedwell, it does give some validation to the CFD predicative modelling which reports a large advancement in performance. Anything less than a great improvement would have suggested otherwise. This experiment sends a strong message that equipment modernisation can greatly aid in plant prosperity.

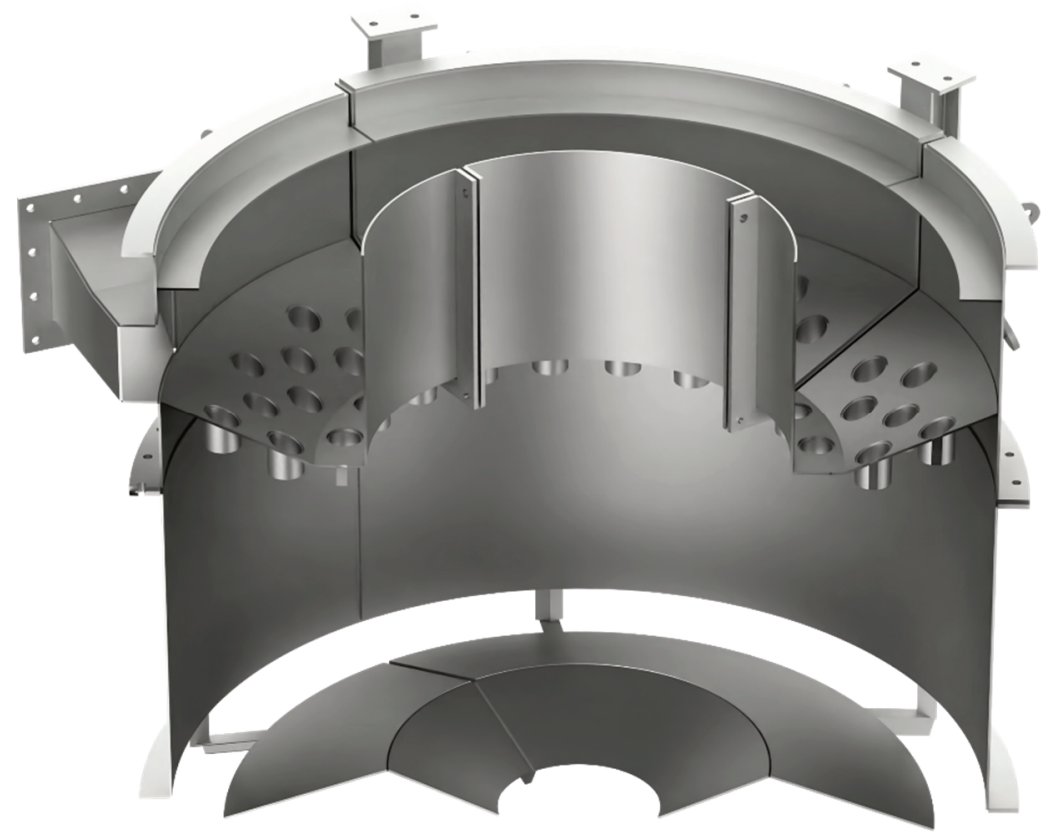

Figure 6 Elevation-cut view of the prototype feedwell displaying transition box, feed trough and underneath the flocculation chamber

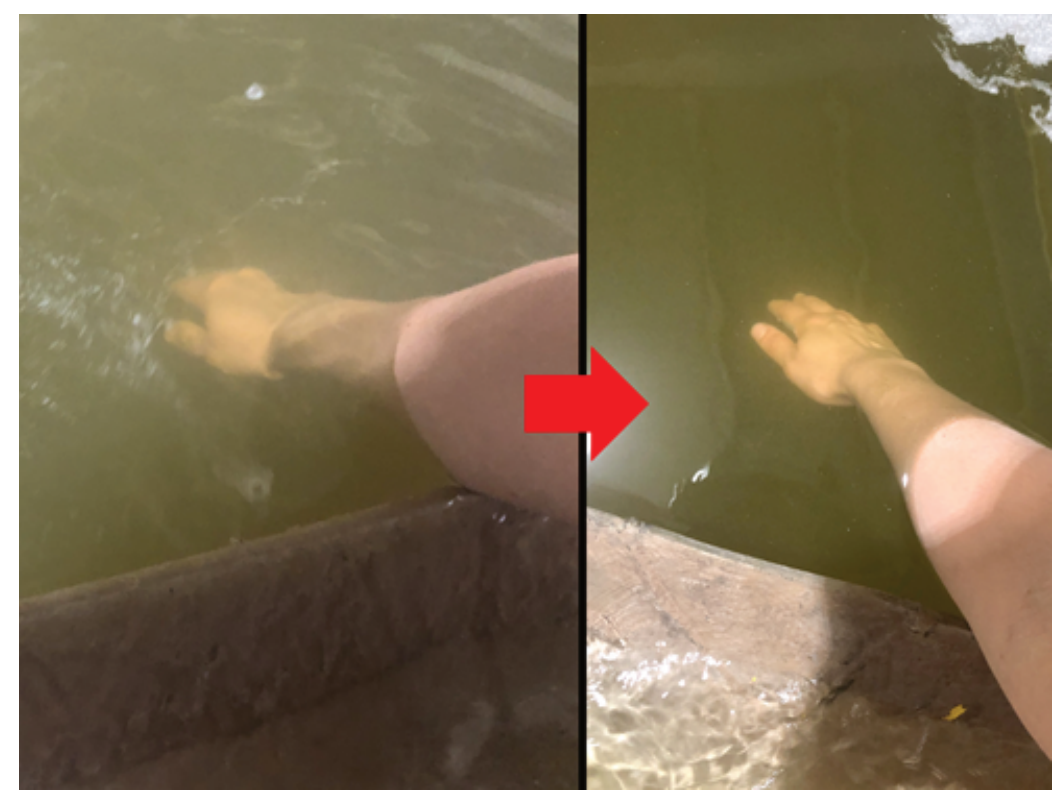

Figure 7 Clarity has visually improved despite the increased average throughput 


\section{Conclusion}

A prospective new small feedwell design has been developed. A process scenario of intermediate difficulty was selected for CFD evaluation and publication; more challenging cases did not detract from performance. The most advanced feature of the new design is its capability of flash mixing liquor with slurry, and consequently its ability to homogenously distribute feed throughout the feedwell. Increased homogeneity improves flocculation and the potential in the application of a clarometer or a camera for optimising flocculant dosing. In comparison to an equivalent Vane Feedwell, numerical modelling shows the new design provides a $50 \%$ increase in solid hold-up. This provides more time for aggregate maturation. Additionally, the four investigated feedwell discharge statistics measuring symmetry of physical quantities show that the new feedwell is superior by 43 to $93 \%$, depending on the parameter. These improvements in symmetry optimise material bed transport, minimise aggregate destruction, and reduce the probability of solids reporting to the overflow.

A high-rate thickener used in an industrial mineral application benefited from the installation of a prototype feedwell. Testing commenced at a throughput equal to that present before the upgrade. After exhibiting a feedwell performance improvement, a higher average throughput was presented to the thickener due to circuit stability. The underflow density increased by an average of $6.5 \% \mathrm{w} / \mathrm{w}-\mathrm{a} 40 \%$ increase. Overflow clarity largely improved, and flocculant consumption reduced by $5 \%$.

The new feedwell design shows promise as a significant advancement in thickening dewatering technology. This work serves as an example of the benefit of modernising thickeners and clarifiers. Currently, work is underway extending the range to larger diameter feedwells.

\section{References}

Fawell, PD, Farrow, JB, Heath, AR, Nguyen, TV, Owen, AT, Paterson, D, Rudman, M, Scales, PJ, Simic, K, Stephens, DW, Swift, JD \& Usher, SP 2009, '20 Years of AMIRA P266 "Improving Thickener Technology" - How has it changed the understanding of thickener performance?', in RJ Jewell, AB Fourie, S Barrera \& J Wiertz (eds), Paste 2009: Proceedings of the Twelfth International Seminar on Paste and Thickened Tailings, Australian Centre for Geomechanics, Perth, pp. 59-68.

Jewell, RJ \& Fourie, AB 2015, 'Thickening', in RJ Jewell \& AB Fourie (eds), Paste and Thickened Tailings - A Guide, 3rd edn, Australian Centre for Geomechanics, Perth. 